\title{
Explants and disaggregated tissue preparations as model systems in nutritional research: advantages and pitfalls
}

\author{
By R. R. DiLs, Department of Physiology $\mathfrak{E}$ Biochemistry, University of Reading, \\ Reading $R G 62 A \mathcal{F}$
}

Organ culture can be defined as the maintenance of tissues in a differentiated functional state in a nutrient medium in vitro (Fell, I976). The technique involves preparing explants (fragments of tissue about $\mathrm{I}-2 \mathrm{~mm}^{3}$ ) in which the thickness of the preparation does not limit the availability of oxygen and nutrients to the cells, especially those at the centre of the explants. The objectives are to maintain the normal development, the structural integrity and architecture, the biochemical functions and hormonal responses of the tissue as closely as possible to those in vivo. These objectives are often achieved by minimizing the growth of the cells in the explants. The time for which explants can be cultured is usually a few days to 2-3 weeks. This has the great advantage over tissue preparations, such as slices, which only remain viable for a few hours in that longer-term experiments such as responsiveness to hormones can be carried out. The objectives of organ culture are therefore different from those of cell culture where cells are no longer organized into tissues and either growth or maintenance of cells is encouraged in vitro. There is a danger of confusion in terminology since tissue culture, which usually implies cell culture, is sometimes used to mean organ culture.

\section{Brief historical background}

One of the earliest uses of organ culture was that of Harrison (1907) who maintained explants of the spinal cord of frog embryos for $\mathrm{I}-4$ weeks by placing them in a drop of clotted lymph, as a supply of nutrients, hanging from a coverslip over a hollowed-out microscope slide. The method was later improved by replacing the flaccid clot of lymph with a solid clot of chicken plasma enriched with chick-embryo extract. A major advance was made by Fell \& Robison (1929) who prepared this clot in a watchglass, placed the explants on the surface of the clot and enclosed the watchglass in a Petri dish containing moist cotton wool. This ensured that the explants were freely exposed to air and minimized the tendency for cells to migrate from the explant. The system was not basically improved on until Trowell (1954) used a stainless-steel grid to support explants at the surface of a liquid medium. With some tissues the explants may need to rest on lens paper, a membrane or a thin layer of agar gel placed on the grid. A liquid medium, which just keeps the explants moist, has the advantage of allowing free diffusion of nutrients, metabolites and gas to the tissue. Added hormones readily dissolve in the medium which can easily be changed during culture. 


\section{Preparation of explants}

After the animal has been killed, the tissue to be explanted is placed rapidly in liquid medium. Depending on the size, fragility, etc. of the tissue some ingenuity may be required to hold the tissue while it is being explanted, but it is essential to keep the tissue and explants moist with culture medium. Explanting is often done with microsurgical instruments such as eye-surgeon's spring-loaded scissors and watch-maker's forceps under a dissecting microscope in a sterile cabinet (for details see Dils \& Forsyth, 1981). Some tissues which are only a few cells thick can be cultured intact without explanting, e.g. the mammary gland of immature female mice (Banerjee et al. 1976).

\section{Organ culture media}

When a tissue is explanted it is deprived 'at a stroke' of its physiological supporting and protective mechanisms. In other words, the extracellular fluids are removed which (a) supply nutrients and $\mathrm{O}_{2}$, (b) remove waste products, (c) maintain extracellular $\mathrm{pH}$ and osmotic pressure, (d) maintain the sterility of the tissue in vivo. Hence a 'life-support system' has to be provided artificially. This consists of a balanced salt solution to maintain osmotic pressure and provide essential ions, supplemented with nutrients such as glucose, amino acids, water-soluble vitamins, fatty acids, etc. This list of ingredients seems to have got longer with time in the search for a universal culture medium.

Though buffering is often provided by using a gas phase of $\mathrm{CO}_{2}-\mathrm{O}_{2}$ (50:950, $\mathrm{v} / \mathrm{v})$ in equilibrium with the sodium bicarbonate in the medium, this can often be replaced by adding HEPES ( $N$-2-hydroxy-ethylpiperazine- $N$ '-2-ethanesulphonic acid) buffer to the medium and culturing in air. HEPES has a convenient $\mathrm{p} K_{a}$ of $7 \cdot 3$ and is non-toxic to most tissues at $20 \mathrm{~mm}$.

The tissue explanted is usually sterile, but the culture medium is ideal for the growth of micro-organisms. Hence good microbial practice is required throughout culture, although low concentrations of antibiotics are often added to the medium. Gentamicin is popular since it is effective against a wide range of bacteria and mycoplasms and it is very stable in the culture medium (see Dils \& Forsyth, 198I).

Organ culture is often carried out in a stationary medium, which can cause the build up of a micro-environment of toxic products at the surface of the explants. A gentle rocking of the medium during culture is therefore advisable. The medium is usually replaced every 24 or $48 \mathrm{~h}$; this is good practice since a very metabolically active tissue could otherwise utilize from the medium a considerable proportion of nutrients, such as glucose.

With tissues such as the pancreas, the rapid accumulation of secreted proteolytic enzymes in the vicinity of the explants has been overcome by circumfusing them with complete- or partial-replacement cycles of medium (Murrell, 1976). With a $3 \mathrm{~h}$ replacement cycle there was good viability of the explants, but no viable cells remained after a $24 \mathrm{~h}$ replacement cycle. It is interesting that with the $3 \mathrm{~h}$ cycle, explant size $\left(2,4\right.$ or $\left.9 \mathrm{~mm}^{3}\right)$ was relatively unimportant. Histological examination 
of the explants showed that a compromise has to be struck between increased surface damage when very small explants are prepared and necrosis at the centre of large explants.

One of the most powerful uses of organ culture is the measurement of responsiveness of tissues to individual hormones or to groups of hormones. When preparing solutions of polypeptide hormones for these experiments it is essential to monitor for loss of hormone if the solution is sterilized by filtration or is prepared or stored in glassware that has not been siliconized. Freidberg et al. (1970) found that the addition of bovine serum albumin to synthetic medium $(25 \mathrm{ml} / \mathrm{l})$ minimized the loss of insulin by adsorption on to glassware, and decreased the minimum effective concentration of insulin in the medium from about 100 to I mM. This type of loss may explain reports that polypeptide hormones must be added to culture medium at apparently high and unphysiological concentrations to be effective.

\section{Role of serum supplements}

Ideally, a chemically defined medium (i.e. without added serum or tissue extracts) is needed for experiments where the effects of hormones or nutrients on explants is being investigated. Although it is sometimes possible to culture successfully embryonic tissues (and other tissues which have not reached terminal differentiation) in chemically defined media, explants from fully developed tissue usually require the addition of $50-100 \mathrm{ml}$ serum (fetal calf serum is often used)/ 1 to the medium to maintain the viability of the tissue. Supplementing the medium with serum is also necessary if encouraging cell growth is the objective of organ-culture experiments.

There has been enormous progress from cell-culture work in identifying the factors in serum which are involved in cell viability, attachment, spreading and growth. It is now opportune that the knowledge gained from cell-culture experiments is transferred to organ culture so that complete or partial replacement of serum by identified factors can be attempted. Ross et al. (1982) have listed the polypeptide growth factors which have been identified in serum, and have placed them in four general categories based on their biological activity and the roles they play in particular physiological events. These categories are: (1) embryonogenesis, normal growth and development; (2) cell and tissue turnover, as related to systems with differing rates of turnover throughout life; (3) proliferative responses associated with cell and tissue injury; (4) the neoplastic phenotype induced by factors from transformed cells.

A more detailed understanding of serum factors involved in the viability and growth of individual cell types would enable organ culture to be used to distinguish between the responses to hormones, etc. of the different types of cells which constitute tissue explants. For further information about serum supplements see Barnes \& Sato (1980 a,b), Ham (1982) and Fischer \& Wieser (1983). 


\section{The gas phase}

For many years the technique of organ culture was largely restricted to embryonic organs, which are resistant to rather anoxic conditions. The general application of the technique was greatly facilitated by Trowell (1954, 1959) who emphasized the importance of $\mathrm{O}_{2}$ and used $95^{\circ} \mathrm{ml} \mathrm{O} / 1$ (plus $50 \mathrm{ml} \mathrm{CO} / 1$ to stabilize the $\mathrm{pH}$ ) as the gas phase to culture successfully some twenty tissues. Present evidence, however, suggests that the optimum gas phase should be critically examined for tissues from individual species. This has been facilitated by the use of HEPES as buffer, which allows the gas phase to be altered independently of the buffering system.

An example of the need for this critical appraisal of the gas phase is shown by mammary gland in culture. Explants from pseudo-pregnant or from mid-pregnant rabbit mammary gland show good preservation of histological structure and respond to prolactin when cultured in an atmosphere containing 200,570 or $950 \mathrm{ml}$ $\mathrm{O}_{2} / 1$ (Dils \& Forsyth, $198 \mathrm{I}$ ), although the effects of hormones on RNA synthesis can be demonstrated in air but not reliably in $95^{\circ} \mathrm{ml} \mathrm{O}_{2} / 1$ (Falconer et al. 1978). Explants from mid-pregnant goat mammary gland can exhibit abnormal growth patterns in $95^{\circ} \mathrm{ml} \mathrm{O} / 1$ but not in air (Dils \& Forsyth, 1981), whereas those from pregnant heifer and ewe mammary gland survive well in $570 \mathrm{ml} \mathrm{O}_{2} / 1$ but poorly in $950 \mathrm{ml} \mathrm{O}_{2} / 1$ (Djiane et al. 1975).

\section{Survey of tissues cultured successfully}

Sharp (1977) has given a useful summary of the appearance and behaviour in culture of the four basic types of animal tissues, and more detailed descriptions for individual tissues can be found in Organ Culture in Biomedical Research, edited by Balls \& Monnickendham (1976). The ease with which connective tissue, e.g. fibrous tissue, cartilage and bone, can be cultured has the unfortunate side-effect that the fibroblast is perhaps the commonest type of cell found in cultures of any animal tissue; it has been described as 'the weed in the tissue culture garden' because it tends to proliferate rapidly and choke the development of other cells, especially when the medium is rich in nutrients. Organ culture has been used to study all three types of muscle tissue (smooth, striped and cardiac) and embryonic muscle tissue is especially easy to culture. Nervous tissue in culture is particularly delicate, and the composition of the culture medium appears to be of greater importance than for most other types of tissue. Of all cell types, culture of epithelial tissue is probably the most studied, especially that of embryonic origin. Although the secretory material produced by epithelial tissue in culture in response to hormones can be recovered from the medium, this appears to be limited by 'closure' of ducts which can occur when the tissue is explanted. This has been likened to wound healing and can result in the entrapment of high-molecularweight material in the lumen of the ductal system whereas low-molecular-weight compounds appear to diffuse out of explants, possibly via 'leaky' tight junctions between the epithelial cells. 


\section{Assessment of tissue response}

Morphological methods. In all culture work careful histological examination is important to determine the responses of the tissue to substances with which it is cultured, and to ensure that its survival is good. Samples of explanted tissue can be removed throughout culture and examined by light microscopy or by electron microscopy of ultra-thin sections after suitable fixation and staining. This enables the maintenance of the structure and the cellular appearance of the tissue to be assessed.

Histochemical and autoradiographic methods. A variety of techniques can be used to analyse the response of explants to hormones, etc. using histologicallyprepared material at either the light or the electron microscopic level. These include autoradiography for the study of DNA or protein synthesis; the use of antibodies labelled with fluorescent dyes or with peroxidase to study secreted proteins or hormone receptors; and quantitative analysis of cell organelles by cytomorphometric techniques. The main problem is that very little material is available, so that micro-methods are essential. This can increase the sensitivity of the measurements but can also increase the degree of possible error.

Since organ culture, by definition, involves explanting tissues composed of different types of cells, the availability of fluorescently-tagged antibodies which recognize specific cell surface components will greatly advance understanding as to which particular type(s) of cells in the explants are responding to hormones, etc. This should also overcome some of the sampling difficulties encountered in comparing results from different cultures of the same tissue and in comparing cultures of different tissues. At present, results are often compared on a wet, dry or defatted dry-weight basis, on total cell protein or on the total number of cells cultured as measured by total DNA or by cell-counting techniques.

Use of inhibitors. Inhibitors have been widely used to analyse the response of explants in culture. For example, mitosis has been inhibited with colchicine, DNA synthesis with 5-bromo-z'-deoxyuridine, RNA synthesis with actinomysin and protein synthesis with cycloheximide or puromycin. The toxicity of such inhibitors should always be investigated; the dose-response and the time-course of response to inhibitors should also be measured, since these may vary with the index of tissue function that is being measured in culture.

Biochemical methods. The range of biochemical changes which can be measured in explants in response to culture with hormones, etc. is usually limited by the small amount of material and hence the sensitivity of the assay method. This often influences the choice between measuring changes which are of metabolic and nutritional significance. Examples of the types of changes which can be measured are (a) the accumulation in explants of tissue-specific products and whether these products are released into the culture medium; (b) changes in the activities of key enzymes, and whether these are accompanied by changes in the amount of enzyme protein due to altered rates of synthesis or degradation of the enzyme, or both; (c) an increasing ability to measure the amount of mRNA in the tissue which specifies the synthesis of a particular enzyme or protein. 
Examples. Our experience on the hormonally-induced synthesis of milk-specific fatty acids by mammary explants from mid-pregnant animals (Forsyth et al. 1972; Strong et al. 1972) led us to investigate the underlying mechanisms of the induction of specific enzymes involved in milk fat synthesis. The results obtained showed, for example, that the rapid increase in the activity of the enzyme fatty acid synthetase in the explants in response to prolactin was due to massive accumulation of the enzyme caused by an increase in its rate of synthesis and a decrease in its rate of degradation (Speake et al. 1976).

Another example is provided by the observation that chick-embryo liver, unlike mammalian fetal liver, has negligible lipogenic capacity. The activities of lipogenic enzymes only increase markedly after hatching, and this can be induced by the administration of insulin and other hormones to 20-d-old chick embryos (Joshi \& Sidbury, 1976; Joshi \& Wakil, 1978). Organ culture of explants of this tissue showed that physiological concentrations of insulin increased the activities and the amounts of key lipogenic enzymes fivefold after $48 \mathrm{~h}$, and that the presence of triiodothyronine and hydrocortisone potentiated the insulin induction by two- and fourfold respectively (Joshi, 1983 ).

Organ culture coupled with biochemical methods has also provided considerable insight into the effects of noradrenaline and insulin on lipogenesis and lipolysis by, for example, rat and human adipose tissue and thereby to an increased understanding of the control of proliferation and maturation of primordial fat cells in normal and obese animals (e.g. Frohlich et al. 1972; Smith, 1974).

\section{Culture of disaggregated tissue}

The advantage of organ culture is that the explants should retain the architecture of the mixed population of cell types which comprise the original tissue. The disadvantages are that it does not allow the individual types of cells which respond in culture to be identified, and that it is limited by the time required to prepare sufficient quantities of viable explants to allow measurement of biochemical changes to be made. Some of these shortcomings can be overcome by using primary culture of cells, although tissue architecture is initially lost, serum or tissue extracts need to be added, and cells isolated from fully-differentiated tissues are often difficult to maintain in vitro.

A 'middle way' which can sometimes be usefully exploited is partially to disaggregate the tissue before culture by controlled digestion with collagenase ( $E C$ 3.4.24.3) and by hyaluronidase (EC 3.2.1.35). The structures obtained are easy and quick to prepare in large numbers and can be separated by size by passage through graded filters. This approach has been used, for example, to prepare multi-alveolar mammary structures from pregnant animals which respond to physiological concentrations of hormones in culture in the absence of added serum, by synthesizing milk fat (Carrington et al. 1983). Although isolated mammary epithelial cells from lactating animals have proved difficult to maintain in culture, alveoli which synthesize lactose when cultured on 'floating' collagen gels in the presence of prolactin and serum can be prepared by controlled digestion of 
lactating mouse mammary gland (Cline et al. 1982). The results obtained from these types of experiments indicate that the shape of the cells, the presence of lactogenic hormones, the maintenance of contact between epithelial cells and the presence of basement-membrane protein (e.g. collagen) are all required to maintain mammary epithelial cell differentiation in culture.

A review of the basement-membrane proteins (collagen, adhesion protein, glycosaminoglycans and proteoglycans) involved in the maintenance of epithelial cells in culture, and details of the preparation from these proteins of reconstructed basement-membrane rafts on which epithelial cells can be cultured, has been written by Reid \& Rojkind (1979).

\section{Conclusions}

The technique of organ culture has not been used very widely for nutritional research. It is hoped that this review has provided sufficient information to allow the reader to evaluate the usefulness and the limitations of the method. This should enable an informed judgement to be made as to whether the time and effort needed to establish the technique are likely to be warranted by the ability to answer specific nutritional questions.

Since the objective of organ culture is to mimic conditions in vivo, it might be useful to end with an example of where failure to do so might lead to new information. Wild \& Kuhn (1979) found that lactose synthesis was markedly depressed in vivo in 14 -d lactating rats which had been permitted only $76 \%$ of the food intake of control rats over the previous 3 weeks. By contrast, no difference in lactose synthesis was observed when mammary acini from these two groups of rats were used. This suggested that some factor circulates in the bloodstream which exerts a controlling influence on lactose synthesis by mammary gland in vivo.

The author would like to thank the Agricultural and Food Research Council for financial support.

\section{REFERENCES}

Balls, M. \& Monnickendham, M. A. (editors) (1976). Organ Culture in Biomedical Research. Cambridge: Cambridge University Press.

Banerjee, M. R., Wood, B. G., Lin, F. K. \& Crump, L. R. (1976). In Tissue Culture Association Manual, vol. 2, pp. $457-466$ [K. K. Sanford, editor]. Rockville, Maryland: Tissue Culture Association.

Barnes, D. \& Sato, G. (1980a). Analytical Biochemistry 102, 255-264.

Barnes, D. \& Sato, G. (1980b). Cell 22, 649-653.

Carrington, C. A., Hosick, H. L., Forsyth, I. A. \& Dils, R. (1983). Fournal of Endocrinology 97 , $157^{-1} 66$.

Cline, P. R., Zamora, P. O. \& Hosick, H. L. (1982). In Vitro 18, 694-702.

Dils, R. \& Forsyth, I. A. (1981). In Methods in Enzymology vol. 72, part D, pp. 724-742 [J. M. Lowenstein, editor]. New York: Academic Press.

Djiane, J., Delouis, C. \& Denamur, R. (1975). Fournal of Endocrinology 65, 453-460.

Falconer, I. R., Forsyth, I. A., Wilson, B. M. \& Dils, R. (1978). Biochemical fournal 172, $509-516$. 
Fell, H. B. (1976). In Organ Culture in Biomedical Research, pp. I-I3 [M. Balls and M. A. Monnickendham, editors]. Cambridge: Cambridge University Press.

Fell, H. B. \& Robison, R. (1929). Biological fournal 23, 767-785.

Fischer, G. \& Wieser, R. J. (editors) (1983). Hormonally Defined Media. Heidelberg: Springer-Verlag.

Forsyth, I. A., Strong, C. R. \& Dils, R. (1972). Biochemical fournal 129, 929-935.

Freidberg, S. H., Oka, T. \& Topper, Y. J. (1970). Proceedings of the National Academy of Sciences, USA 67, 1493-1495.

Frohlich, J., Vast, A. \& Hollenberg, C. H. (1972). Biochimica et Biophysica Acta 280, 579-587.

Ham, R. G. (1982). In Growth of Cells in Hormonally Defined Media, pp. 39-60 [G. H. Sato, A. B. Pardee and D. A. Sirbasku, editors]. Cold Spring Harbor: Cold Spring Harbor Laboratory.

Harrison, R. G. (1907). Proceedings of the Society of Experimental Biology and Medicine 4, 140-143.

Joshi, V. C. (1983). In Methods in Enzymology, vol. 72, part D, pp. 743-747 [J. M. Lowenstein, editor]. New York: Academic Press.

Joshi, V. C. \& Sidbury, J. B. (1976). Archives of Biochemistry and Biophysics 173, 403-414.

Joshi, V. C. \& Wakil, S. J. (1 978). Journal of Biological Chemistry 253, $2120-2128$.

Murrell, L. R. (1976). In Organ Culture in Biomedical Research, pp. 273-292 [M. Balls and M. A. Monnickendham, editors]. Cambridge: Cambridge University Press.

Reid, L. M. \& Rojkind, M. (1979). In Methods in Enzymology, vol. 58, pp. 263-278 [W. J. Jakoby and I. H. Paston, editors]. New York: Academic Press.

Ross, R., Raines, E., Bowen-Pope, D. \& Glenn, K. (1982). In Growth of Cells in Hormonally Defined Media, pp. 27-35 [G. H. Sato, A. B. Pardee and D. A. Sirbasku, editors]. Cold Spring Harbor: Cold Spring Harbor Laboratory.

Sharp, J. A. (1977). An Introduction to Animal Tissue Culture, Studies in Biology, no. 82. London: Edward Arnold.

Smith, U. (1974). Fournal of Clinical Investigation 53, 91-98.

Speake, B. K., Dils, R. \& Mayer, R. J. (1976). Biochemical fournal 154, 359-370.

Strong, C. R., Forsyth, I. A. \& Dils, R. (I972). Biochemical fournal I 28, 509-519.

Trowell, O. A. (1954). Experimental Cell Research 6, 1246-1248.

Trowell, O. A. (1959). Experimental Cell Research 16, I $18-121$.

Wild, C. J. \& Kuhn, N. J. (1979). Biochemical Journal 182, 287-294. 